\title{
Comparative Study of Discrete Component Realizations of Fractional-Order Capacitor and Inductor Active Emulators*
}

\author{
Georgia Tsirimokou ${ }^{\dagger, \S}$, Aslihan Kartci ${ }^{\text {, }}$, Jaroslav Koton ${ }^{\ddagger}$, \\ Norbert Herencsar ${ }^{\ddagger * * *}$ and Costas Psychalinos ${ }^{\dagger, \dagger \dagger}$ \\ ${ }^{\dagger}$ Physics Department, \\ University of Patras, \\ Electronics Laboratory, University Campus, \\ Rio Patras, GR 26504, Greece \\ $\$$ Faculty of Electrical Engineering and Communication, \\ Brno University of Technology, \\ Technicka 12, Brno 616 00, Czech Republic \\ \$tsirimg@upatras.gr \\ \$kartci@feec.vutbr.cz \\ "koton@feec.vutbr.cz \\ **herencsn@feec.vutbr.cz \\ ${ }^{\dagger}$ cpsychal@upatras.gr
}

Received 26 October 2017

Accepted 4 December 2017

Published 19 January 2018

\begin{abstract}
Due to the absence of commercially available fractional-order capacitors and inductors, their implementation can be performed using fractional-order differentiators and integrators, respectively, combined with a voltage-to-current conversion stage. The transfer function of fractional-order differentiators and integrators can be approximated through the utilization of appropriate integer-order transfer functions. In order to achieve that, the Continued Fraction Expansion as well as the Oustaloup's approximations can be utilized. The accuracy, in terms of magnitude and phase response, of transfer functions of differentiators/integrators derived through the employment of the aforementioned approximations, is very important factor for achieving high performance approximation of the fractional-order elements. A comparative study of the accuracy offered by the Continued Fraction Expansion and the Oustaloup's approximation is performed in this paper. As a next step, the corresponding implementations of the emulators of the fractional-order elements, derived using fundamental active cells such as operational amplifiers, operational transconductance amplifiers, current conveyors, and current feedback operational amplifiers realized in commercially available discrete-component IC form,
\end{abstract}

\footnotetext{
*This paper was recommended by Regional Editor Piero Malcovati.

$\dagger \dagger$ Corresponding author.

This is an Open Access article published by World Scientific Publishing Company. It is distributed under the terms of the Creative Commons Attribution 4.0 (CC-BY) License. Further distribution of this work is permitted, provided the original work is properly cited.
} 


\section{G. Tsirimokou et al.}

are compared in terms of the most important performance characteristics. The most suitable of them are further compared using the OrCAD PSpice software.

Keywords: Continued Fraction Expansion; Oustaloup's approximation; current conveyor; current feedback operational amplifier; fractional-order differentiator; fractional-order integrator; op-amp; operational transconductance amplifier.

\section{Introduction}

Owing to the interdisciplinary nature of the fractional calculus, ${ }^{1}$ there is a growing research interest in the development of fractional-order circuits including filters, ${ }^{2-9}$ oscillators, ${ }^{10-13}$ biological tissues emulators, ${ }^{14}$ and energy storage devices. ${ }^{15}$ In these applications, the basic building blocks are the fractional-order capacitors and/or fractional-order inductors.

The impedance of fractional-order capacitor, is described by the expression in (1), where $0<\alpha<1$ is the order of the element and $C_{\alpha}$ is the pseudo-capacitance in units of Farad $/ \mathrm{s}^{(1-\alpha)} \cdot{ }^{16}$

$$
Z_{\mathrm{CPE}}(s)=\frac{1}{C_{\alpha} s^{\alpha}}
$$

The value of the conventional capacitance $(C)$ in Farad equivalent in its impedance at specific frequency $(\omega)$ to the fractional-order capacitor can be obtained by the formula in (2).

$$
C=\frac{C_{\alpha}}{\omega^{1-\alpha}} .
$$

The impedance of a fractional-order inductor is described by the expression in (3), where $0<\beta<1$ is the order of the inductor and $L_{\beta}$ is the pseudo-inductance in Henry/s ${ }^{(1-\beta)}$.

$$
Z_{\mathrm{FI}}(s)=L_{\beta} s^{\beta} .
$$

The value of the conventional inductance $(L)$ in Henry equivalent in its impedance at specific frequency $(\omega)$ to the fractional-order inductor can be obtained by the formula in (4).

$$
L=\frac{L_{\beta}}{\omega^{1-\beta}} .
$$

The straightforward procedure for implementing these types of circuits is the substitution of the integer-order elements by fractional-order ones. Unfortunately, these elements are not yet commercially available ${ }^{17-19}$ and, therefore, they have to be approximated by appropriate integer-order networks. A possible solution for approximating fractional-order capacitors is the employment of an RC network, ${ }^{20-22}$ but this suffers from the requirement for re-designing the network in order to change the characteristics of the fractional-order element. The behavior of fractional-order inductors is approximated through the combination of a fractional-order capacitor 
emulator and a Generalized Impedance Converter (GIC). ${ }^{23,6}$ Another solution, offering more design flexibility than that offered by the previous one, is the employment of fractional-order integrator/differentiation stage and, also, an appropriate voltage-to-current $(V / I)$ converter. ${ }^{24,25}$ The fractional-order integrator/differentiator is approximated by an appropriate integer-order transfer function and the achieved accuracy depends on the order of approximation which reflects into the circuit complexity required for implementing the corresponding transfer function. Therefore, the aim of this paper is to provide a useful comparative performance study offered by various orders of approximations of these stages. Hence, the performance of the 2nd to 5th-order approximations of the Continued Fraction Expansion $(\mathrm{CFE})^{26}$ are evaluated and compared with those offered by the 3rd and 5th-order Oustaloup's approximation. ${ }^{27}$ The paper is organized as follows: in Sec. 2, the concept for emulating fractional-order capacitors and inductors is briefly presented and the expressions of approximations of the integro-differential operator in the Laplace domain are presented and evaluated in terms of magnitude and phase response. The implementation of the most suitable approximation is presented in Sec. 3, using discrete-component IC forms of operational amplifiers (op-amps), operational transconductance amplifiers (OTAs), second-generation current conveyors (CCIIs), and current feedback operational amplifiers (CFOAs). The comparison results, obtained using the OrCAD PSpice software, are presented in Sec. 4.

\section{Approximation of Fractional-Order Elements}

\subsection{Functional block diagram (FBD)}

The emulation of a fractional-order capacitor/inductor is performed according to the concept demonstrated in Fig. 1 . In the case that $r=\alpha$, a fractional-order capacitor is emulated with equivalent impedance, defined as $Z_{\text {eq }} \equiv v / i$, given by Eq. (5).

$$
Z_{\mathrm{eq}, \mathrm{CPE}}(s)=\frac{1}{g_{m, V I} \cdot(\tau s)^{\alpha}} .
$$

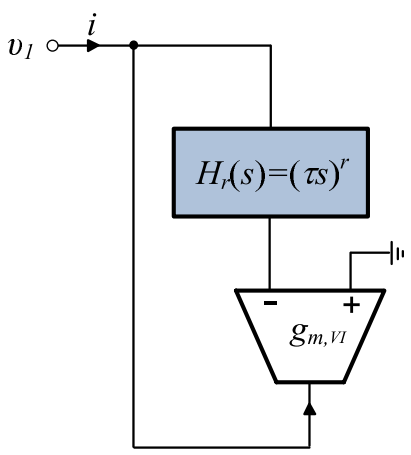

Fig. 1. Concept for emulating fractional-order capacitor/inductor. 


\section{G. Tsirimokou et al.}

A fractional-order inductor is emulated in the case that $r=-\beta$, with equivalent impedance given by Eq. (6)

$$
Z_{\mathrm{eq}, \mathrm{FI}}(s)=\frac{(\tau s)^{\beta}}{g_{m, V I}} .
$$

Therefore, a fractional-order differentiator is utilized in the case of fractional-order capacitor emulation, with unity-gain frequency $\left(\omega_{0}\right)$ given by the formula: $\omega_{0}=1 / \tau$. In the case of fractional-order inductor, a fractional-order integrator with the same unity-gain frequency is employed. Inspecting Eqs. (5)-(6), it is derived that the transconductance $g_{m, V I}$ of the $V / I$ converter determines the impedance of the emulated element at the center frequency $\omega_{0}$, i.e., $Z\left(\omega_{0}\right)=1 / g_{m, V I}$. Using Eqs. (1) and (3), the pseudo-capacitance and the pseudo-inductance design equations are given by Eq. (7)

$$
C_{\alpha}=g_{m, V I} \cdot \tau^{\alpha}, \quad L_{\beta}=\frac{\tau^{\beta}}{g_{m, V I}} .
$$

De-normalizing at the unity-gain frequency $\omega_{0}$, the capacitance and the inductance take the forms of $(8)$

$$
C=\frac{g_{m, V I}}{\omega_{0}^{\alpha} \cdot \omega^{1-\alpha}}, \quad L=\frac{1}{g_{m, V I} \cdot \omega_{0}^{\beta} \cdot \omega^{1-\beta}} .
$$

Selecting $\omega=\omega_{0}$, in (8) yields the values of the de-normalized capacitance and inductance as

$$
C=\frac{g_{m, V I}}{\omega_{0}}, \quad L=\frac{1}{g_{m, V I} \cdot \omega_{0}} .
$$

\subsection{Approximation of the Laplace operator}

From the discussion in Sec. 2.1, it is obvious that the level of accuracy of the fractional integro-differential operator in the Laplace domain $\left(s^{r}\right)$ is very critical for the emulation of the corresponding fractional-order element. The $n$ th-order approximation of the operator around a center frequency $\omega_{0}=1 \mathrm{rad} / \mathrm{s}$, is expressed by a rational function defined by the quotient of two polynomials of the variable $s$ :

$$
s^{r} \cong \frac{\left(\frac{a_{0}}{a_{n}}\right) s^{n}+\left(\frac{a_{1}}{a_{n}}\right) s^{n-1}+\cdots+\left(\frac{a_{n-1}}{a_{n}}\right) s+1}{s^{n}+\left(\frac{a_{n-1}}{a_{n}}\right) s^{n-1}+\cdots+\left(\frac{a_{1}}{a_{n}}\right) s+\frac{a_{0}}{a_{n}}} .
$$

where in Eq. (10) $a_{i}(i=0 \ldots n)$ are positive real coefficients. In the case of $r=\alpha$ with $0<\alpha<1$ the expression represents a fractional-order differentiator with unitygain frequency $\omega_{0}=1 \mathrm{rad} / \mathrm{s}$, while for $r=-\beta$, with $0<\beta<1$, a fractional-order integrator (with the same unity-gain frequency). The values of the coefficients $a_{i}$, for $n=2 \ldots 5$, are summarized in Tables 1 and $2 .{ }^{26}$ 
Table 1. Coefficients values of the CFE approximation $n=2, n=3, n=4$.

\begin{tabular}{lccc}
\hline Coefficient & $n=2$ & $n=3$ & $n=4$ \\
\hline$a_{0}$ & $r^{2}+3 r+2$ & $r^{3}+6 r^{2}+11 r+6$ & $r^{4}+10 r^{3}+35 r^{2}+50 r+24$ \\
$a_{1}$ & $8-2 r^{2}$ & $-3 r^{3}-6 r^{2}+27 r+54$ & $-4 r^{4}-20 r^{3}+40 r^{2}+320 r+384$ \\
$a_{2}$ & $r^{2}-3 r+2$ & $3 r^{3}-6 r^{2}-27 r+54$ & $6 r^{4}-150 r^{2}+864$ \\
$a_{3}$ & - & $-r^{3}+6 r^{2}-11 r+6$ & $-4 r^{4}+20 r^{3}+40 r^{2}-320 r+384$ \\
$a_{4}$ & - & - & $r^{4}-10 r^{3}+35 r^{2}-50 r+24$ \\
$a_{5}$ & - & - & - \\
\hline
\end{tabular}

Table 2. Coefficients values of the CFE approximation (for $n=5)$.

\begin{tabular}{lc}
\hline Coefficient & $n=5$ \\
\hline$a_{0}$ & $-r^{5}-15 r^{4}-85 r^{3}-225 r^{2}-274 r-120$ \\
$a_{1}$ & $5 r^{5}+45 r^{4}+5 r^{3}-1005 r^{2}-3250 r-3000$ \\
$a_{2}$ & $-10 r^{5}-30 r^{4}+410 r^{3}+1230 r^{2}-4000 r-12000$ \\
$a_{3}$ & $10 r^{5}-30 r^{4}-410 r^{3}+1230 r^{2}+4000 r-12000$ \\
$a_{4}$ & $-5 r^{5}+45 r^{4}-5 r^{3}-1005 r^{2}+3250 r-3000$ \\
$a_{5}$ & $r^{5}-15 r^{4}+85 r^{3}-225 r^{2}+274 r-120$ \\
\hline
\end{tabular}

Employing the Oustaloup's approximation method, the corresponding expression, for geometrically distributed frequencies over the band $\left[\omega_{b}, \omega_{h}\right]$, is the following:

$$
s^{r} \cong C \cdot \prod_{k=-N}^{N} \frac{s+\omega_{k}^{/}}{s+\omega_{k}}=\frac{B_{n} s^{n}+B_{n-1} s^{n-1}+\cdots+B_{1} s+B_{0}}{s^{n}+A_{n-1} s^{n-1}+\cdots+A_{1} s+A_{0}} .
$$

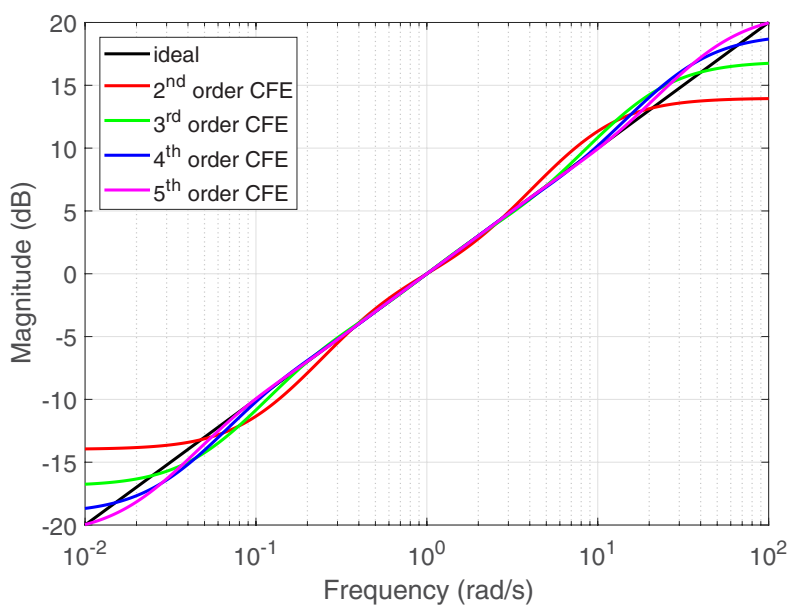

(a)

Fig. 2. Frequency responses of the variable $s^{0.5}$ using the CFE approximation (a) magnitude and (b) phase. 
G. Tsirimokou et al.

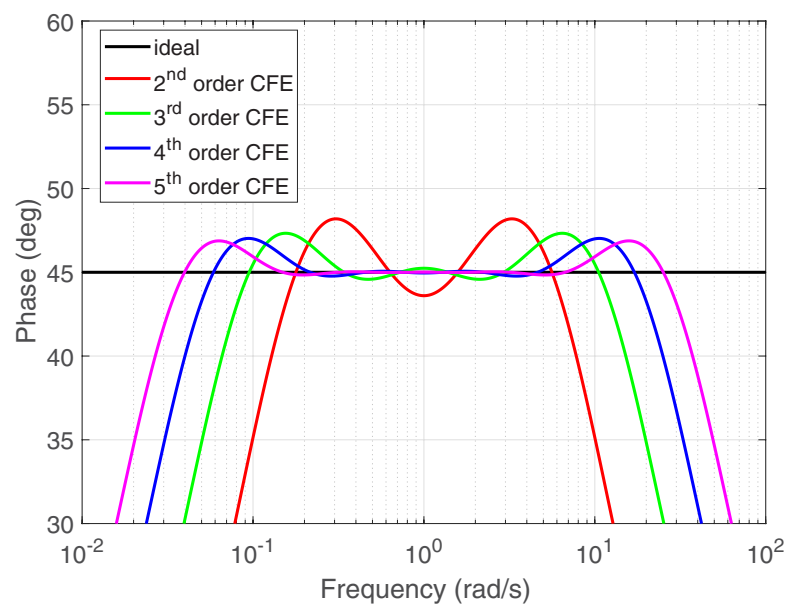

(b)

Fig. 2. (Continued)

Here, the variables $\omega_{k}^{\prime}, \omega_{k}$, and $C$ in Eq. (11) are defined by Eq. (12):

$$
\omega_{k}^{\prime}=\omega_{b} \cdot\left(\frac{\omega_{h}}{\omega_{b}}\right)^{\frac{k+N+0.5 \cdot(1-r)}{2 N+1}}, \quad \omega_{k}=\omega_{b} \cdot\left(\frac{\omega_{h}}{\omega_{b}}\right)^{\frac{k+N+0.5 \cdot(1+r)}{2 N+1}}, \quad C=\omega_{h}^{r} .
$$

Owing to the geometrical distribution of frequencies, the unity-gain frequency $\left(\omega_{0}\right)$ is calculated according to the formula: $\omega_{0}=\sqrt{\omega_{b} \cdot \omega_{h}}$. It must be also mentioned that

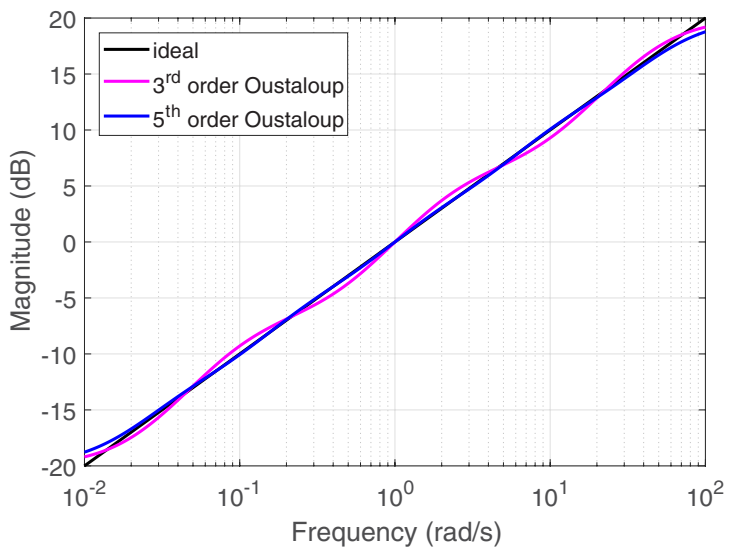

(a)

Fig. 3. Frequency responses of the variable $s^{0.5}$ using the Oustaloup's approximation (a) magnitude and (b) phase. 


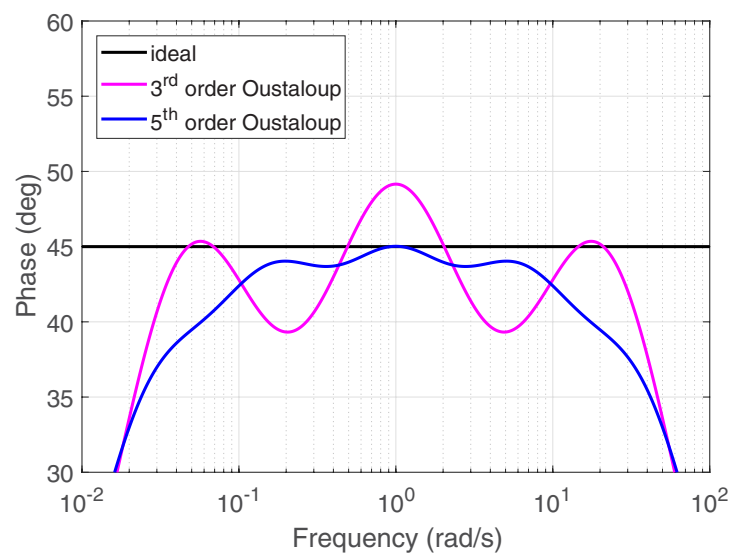

(b)

Fig. 3. (Continued)

the order of the transfer function is $n=2 N+1$ and, therefore, only odd-order approximations are possible through the Oustaloup's method.

Using the FOMCON Toolbox of MATLAB, ${ }^{28}$ the obtained magnitude and phase responses in frequency domain of the 2nd and 5th-order approximations of the variable $s^{0.5}$ using CFE method are provided in the plots in Fig. 2.

The corresponding plots for the 3rd and 5th-order Oustaloup's approximation (i.e., $N=1,2)$, for $\left[\omega_{b}, \omega_{h}\right]=\left[10^{-2} \mathrm{rad} / \mathrm{s}, 10^{2} \mathrm{rad} / \mathrm{s}\right]$, are given in Fig. 3 . In order to

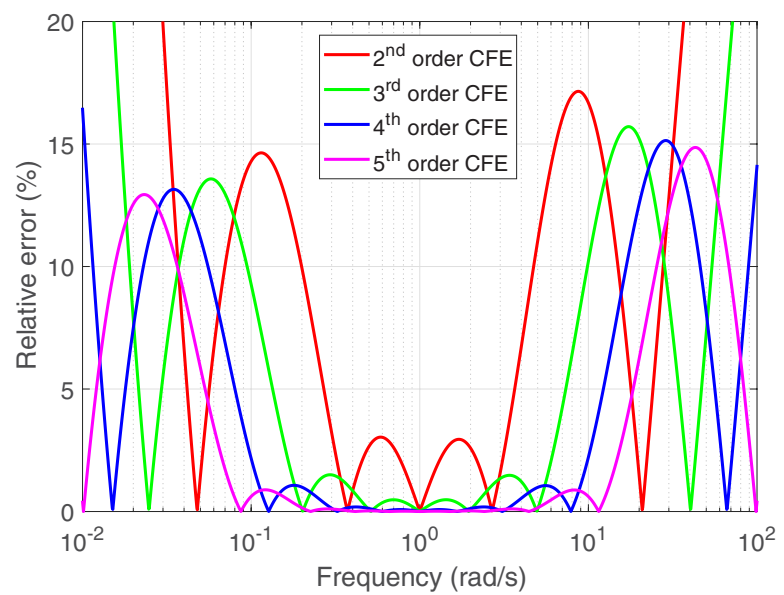

(a)

Fig. 4. Error plots for CFE approximation (a) magnitude and (b) phase. 
G. Tsirimokou et al.

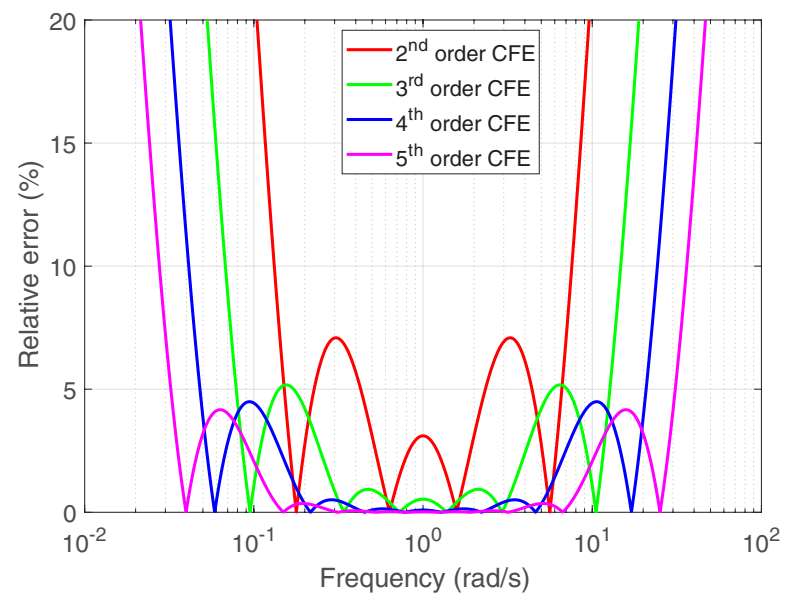

(b)

Fig. 4. (Continued)

summarize the performance comparison, the corresponding error plots for CFE approximation are given in Fig. 4. The corresponding plots for the Oustaloup's approximation are provided in Fig. 5. In addition, the performance of the approximations in terms of accuracy is summarized in Table 3.

According to the provided results, the conclusions are the following: (i) Comparing the accuracy of the 3rd-order CFE and Oustaloup's approximations, it is obvious that $\mathrm{CFE}$ is more efficient. In addition, CFE approximation offers also 2nd

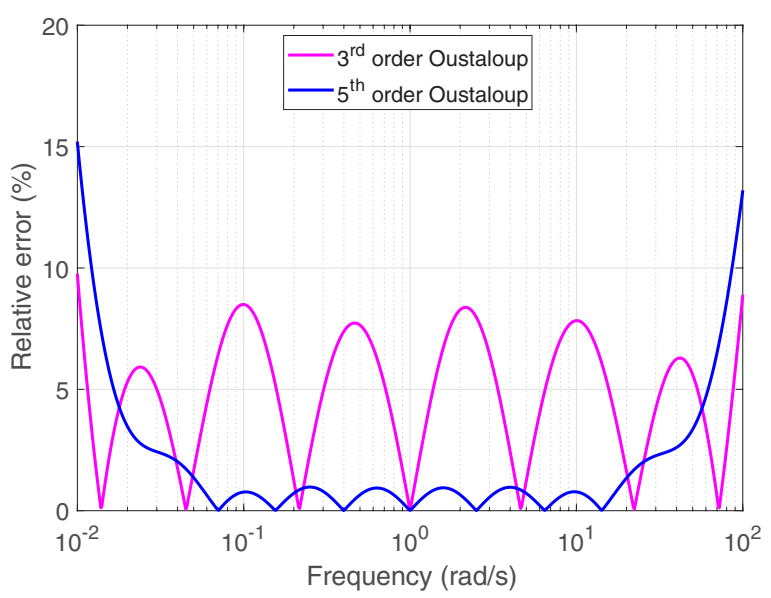

(a)

Fig. 5. Error plots for Oustaloup's approximation (a) magnitude and (b) phase. 


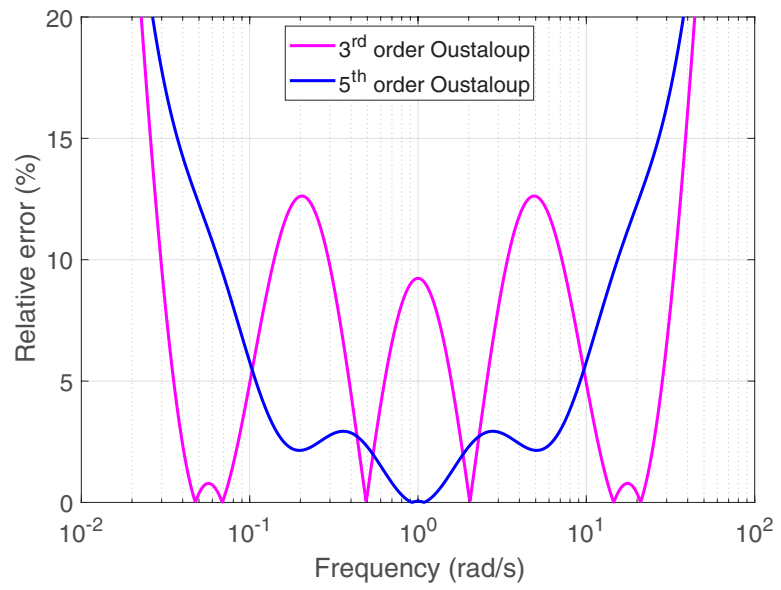

(b)

Fig. 5. (Continued)

Table 3. Performance comparison results for CFE and Oustaloup's approximations.

\begin{tabular}{lcc}
\hline Approximation & $\begin{array}{c}\text { Bandwidth for magnitude } \\
\text { error }<5 \%(\mathrm{rad} / \mathrm{s})\end{array}$ & $\begin{array}{c}\text { Bandwidth for phase } \\
\text { error }<5 \%(\mathrm{rad} / \mathrm{s})\end{array}$ \\
\hline CFE $(n=2)$ & {$[0.27,3.65]$} & {$[0.43,2.34]$} \\
CFE $(n=3)$ & {$[0.13,7.34]$} & {$[0.17,5.82]$} \\
CFE $(n=4)$ & {$[0.08,12.35]$} & {$[0.048,20.88]$} \\
CFE $(n=5)$ & {$[0.053,18.52]$} & {$[0.032,31]$} \\
OUST. $(N=1)$ & {$[0.71,1.38]$} & {$[0.39,0.63]$} \\
OUST. $(N=2)$ & {$[0.016,62]$} & {$[0.1,9]$} \\
\hline
\end{tabular}

and 4th-order approximations. This is very important, because using the CFE relatively simple circuits are possible to design approximating fractional-order transfer function. $^{3}$ (ii) In the case of 5th-order of approximation, the Oustaloup's method offers more accuracy in magnitude than that offered by the CFE method. On the other hand, the CFE is more efficient in terms of phase accuracy.

\section{Realizations of Fractional-Order Capacitor and Inductor Emulators}

As Eqs. (10)-(11) have the same general form, they can be implemented by the same topology. Thus, the Follow-the-Leader Feedback (FLF) and Inverse-Follow-theLeader-Feedback (IFLF) structures, ${ }^{29}$ represented by the FBDs in Figs. 6(a) and 6(b), respectively, can be utilized for this purpose. 


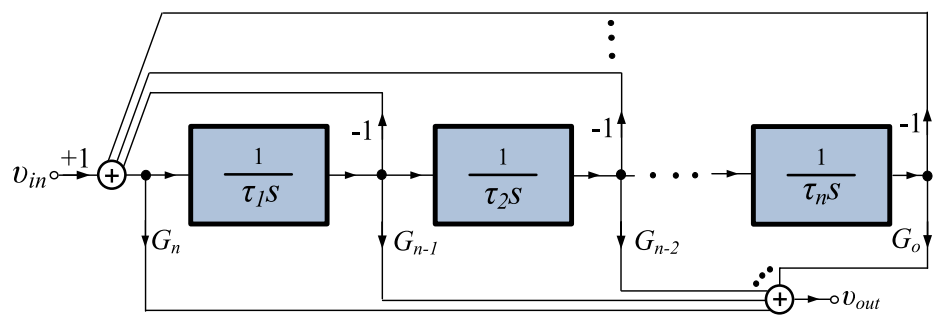

(a)

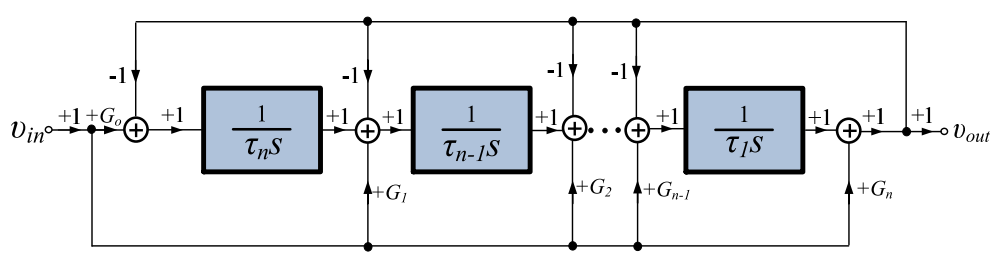

(b)

Fig. 6. Multi-feedback structures for realizing differentiators or integrators according to the CFE and Oustaloup's approximations (a) FLF and (b) IFLF.

The transfer function realized by both schemes is given by Eq. (13)

$$
H(s)=\frac{G_{n} s^{n}+\left(\frac{G_{n-1}}{\tau_{1}}\right) s^{n-1}+\cdots+\left(\frac{G_{0}}{\tau_{1} \cdot \tau_{2} \ldots \tau_{n}}\right)}{s^{n}+\left(\frac{1}{\tau_{1}}\right) s^{n-1}+\cdots+\left(\frac{1}{\tau_{1} \cdot \tau_{2} \ldots \tau_{n}}\right)} .
$$

The calculation of the time-constants $\tau_{i}(i=1 \ldots n)$ and gain-factors $G_{j}(j=0 \ldots n)$ is performed by equating the corresponding coefficients of the polynomials in Eq. (10) or (11) with those in Eq. (13). It should be mentioned at this point that both integrator and differentiator can be implemented by the same structure, just by appropriately selecting the values of time-constants and gain factors. Consequently, both types of fractional-order elements can be emulated and this is very attractive from the design flexibility point of view.

The implementation of the FBD in Fig. 1, using op-amps as active elements for realizing the lossless integration and summation stages ${ }^{29}$ in the case of a 5 th-order approximation, is depicted in Fig. 7. Note that an input buffer is employed in order to implement the required high input impedance of the integration/differentiation stage. In addition, the employed OTA, with transconductance $g_{m, V I}$, performs the required $V / I$ conversion. The realized time-constants and gain-factors are given by the expressions in Eqs. (14) and (15), respectively.

$$
\tau_{i}=R \cdot C_{i} \quad(i=1 \ldots 5) .
$$




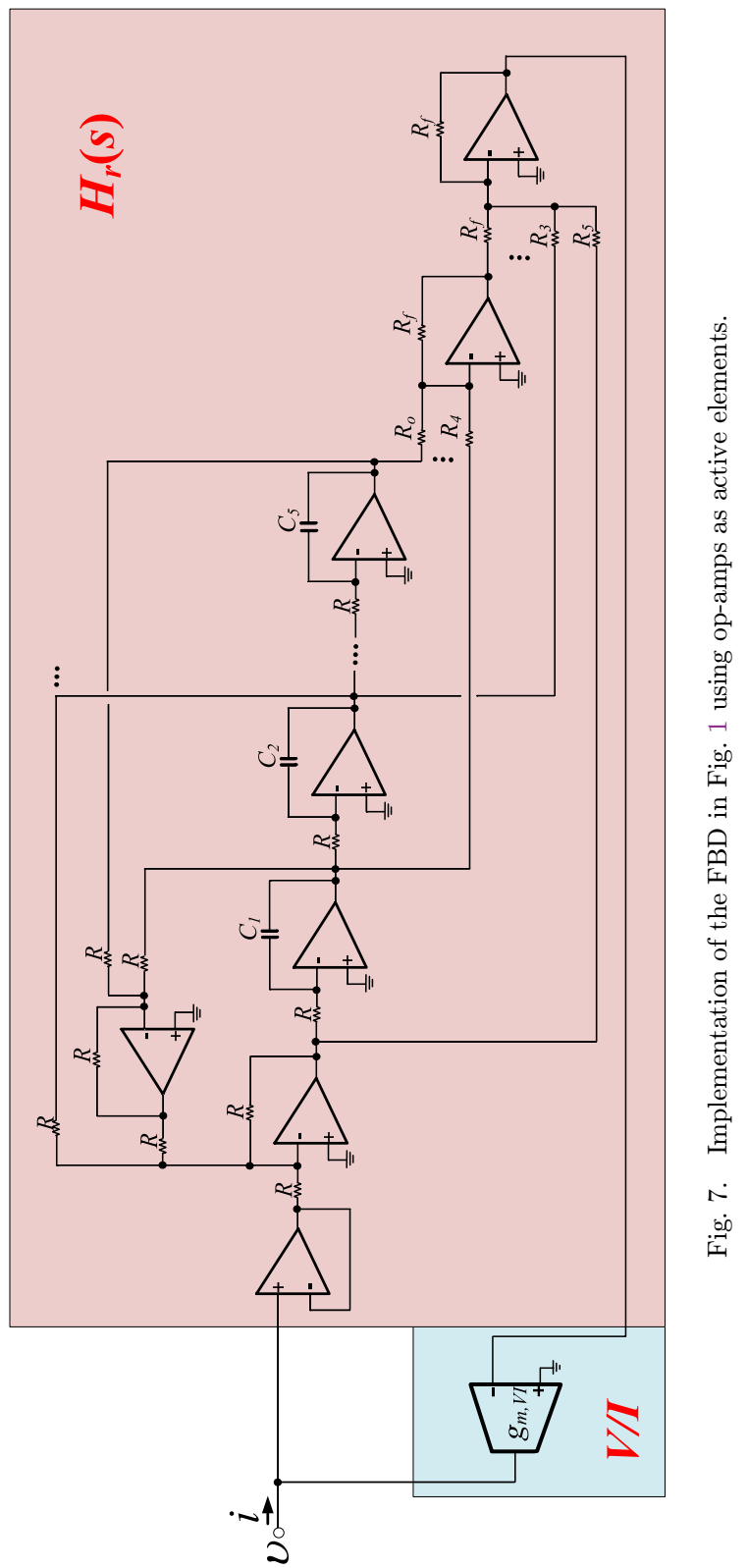


G. Tsirimokou et al.

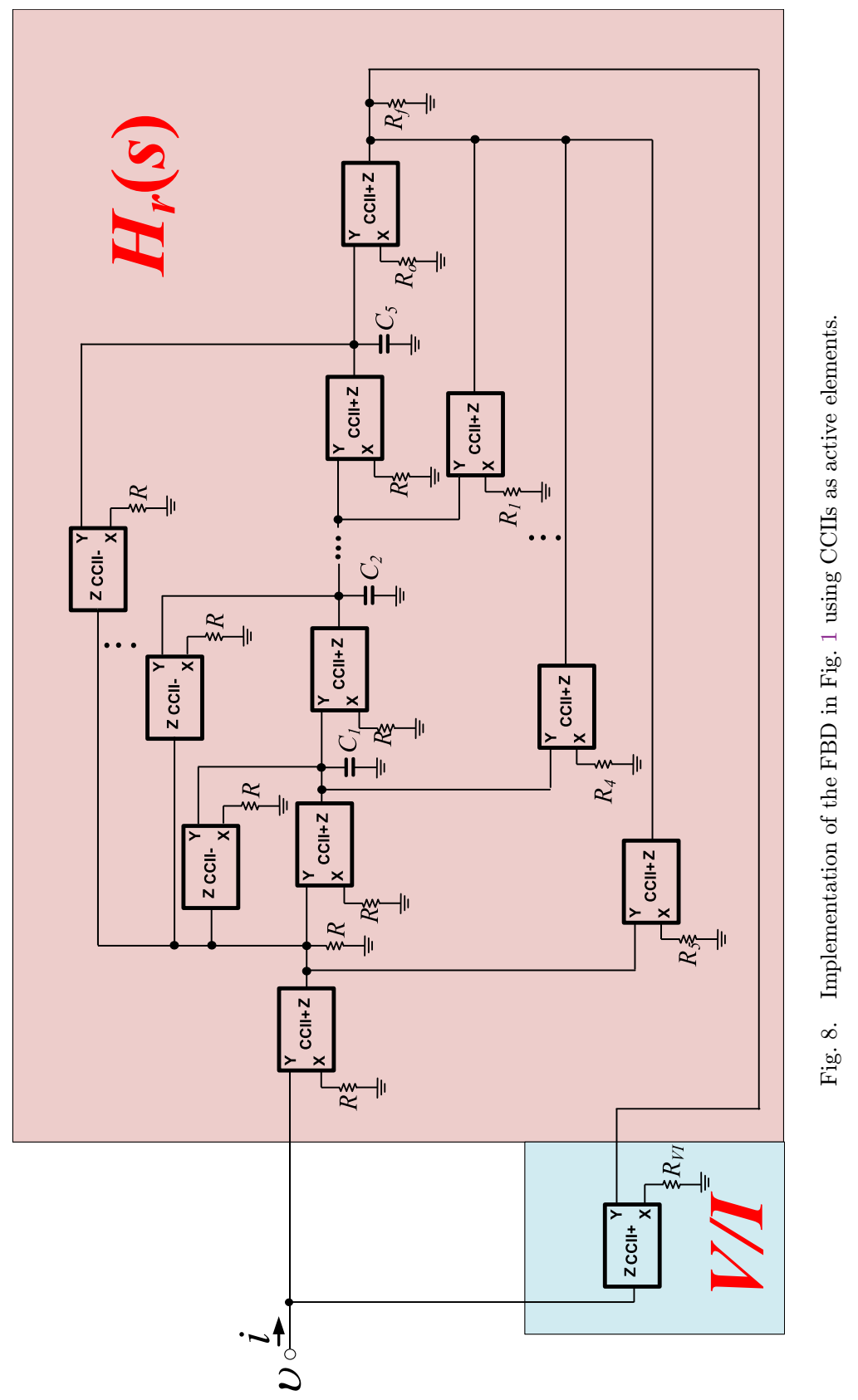


Comparative Study of Discrete Component Realizations of CPE/FI Active Emulators

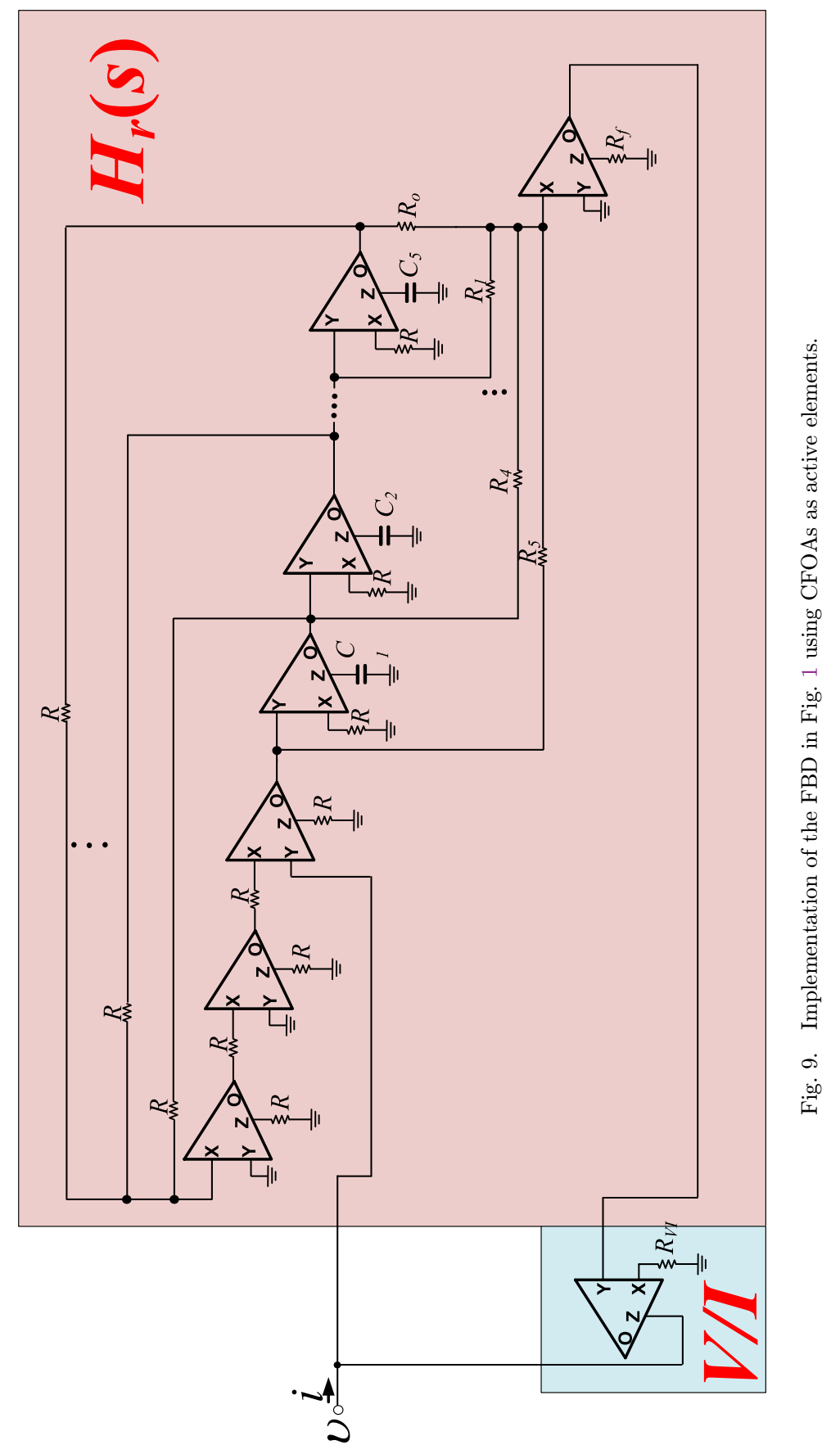


G. Tsirimokou et al.

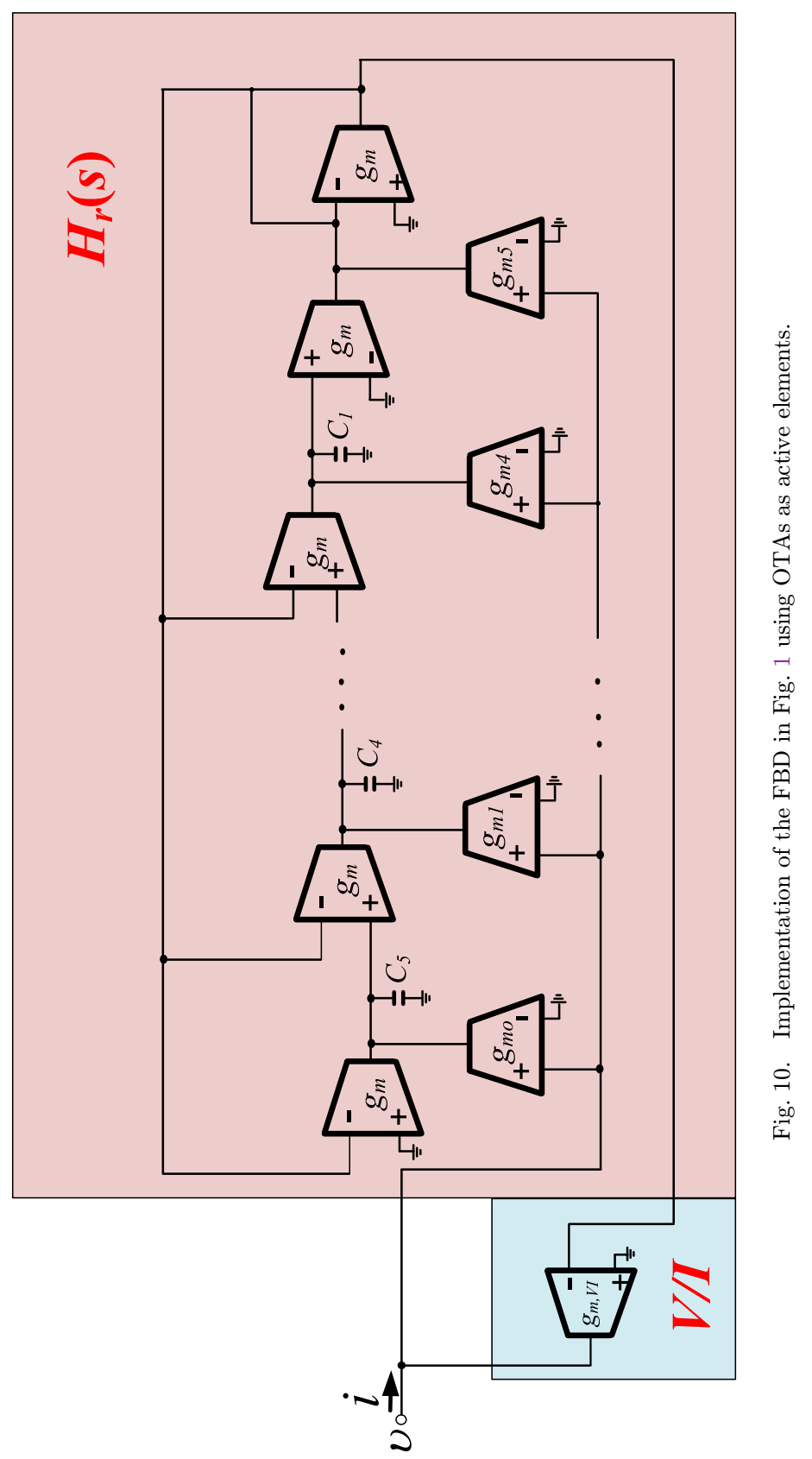


Table 4. Performance comparison results for implementations of FBDs in Fig. 1.

\begin{tabular}{lcccc}
\hline Factor & FLF with op-amps & FLF with CCIIs & FLF with CFOAs & IFLF with OTAs \\
\hline Active elements & 10 plus 1 OTA & $23^{\mathrm{a}}$ & 10 & 14 \\
Capacitors & 5 & 5 & 5 & 5 \\
Resistors & 23 & 20 & 22 & $14^{\mathrm{b}}$ \\
\hline
\end{tabular}

Notes: Table notes. ${ }^{\text {a }}$ Two CCII+ ICs are required for implementing a CCII-. ${ }^{31}$

${ }^{\mathrm{b}}$ For controlling the transconductance of OTAs.

$$
G_{j}=\frac{R_{f}}{R_{j}} \quad(j=0 \ldots 5) .
$$

The corresponding implementation using CCIIs as active elements ${ }^{30}$ is demonstrated in Fig. 8, where the $V / I$ conversion is performed by a CCII- conveyor with a resistor $R_{V I}=1 / g_{m, V I}$ connected at its low-impedance input (X) terminal. The expressions of time-constants and gain-factors are still given by Eqs. (14) and (15), respectively.

Using CFOAs as active elements, ${ }^{31}$ the resulted implementation is shown in Fig. 9. The $V / I$ conversion is performed through a CFOA with a resistor $R_{V I}=$ $1 / g_{m, V I}$ associated with its $X$ terminal. The design equations are the same as in previous cases.

Inspecting Fig. 6, it is concluded that the IFLF form is suitable only for elements with inherent differential operation, such as OTAs. ${ }^{32}$ Thus, the OTA-C implementation of the FBD in Fig. 1 is demonstrated in Fig. 10. The realized time-constants, as well as the gain-factors, are expressed by Eqs. (16) and (17), respectively.

$$
\begin{aligned}
\tau_{i} & =\frac{C_{i}}{g_{m}} \quad(i=1 \ldots 5) . \\
G_{j} & =\frac{g_{m j}}{g_{m f}} \quad(j=0 \ldots 5) .
\end{aligned}
$$

Considering that the active elements are available as commercially discretecomponent ICs, Table 4 compares the circuit complexity of the corresponding realizations of the FBDs in Fig. 1, in the case of a 5th-order approximation. According to the provided results, the best option in terms of active component count is the FLF structure implemented using CFOAs as active elements.

\section{Simulation and Comparison Results}

In order to verify the results obtained in Sec. 2.2, fractional-order capacitors with capacitance $C=6.3 \mu \mathrm{F}$ at center frequency $f_{0}=100 \mathrm{~Hz}$ and orders $\alpha=\{0.3,0.5,0.7\}$ will be emulated using the topology in Fig. 9. Using Eq. (2), the corresponding values of the pseudo-capacitance were: $0.57 \mathrm{~F} / \mathrm{s}^{0.7}, 0.16 \mathrm{~F} / \mathrm{s}^{0.5}$, and $0.043 \mathrm{~F} / \mathrm{s}^{0.3}$, respectively. According to Eq. (9), the transconductance of the $V / I$ converter must be: $g_{m, V I}=10 \mu \mathrm{S}$ or, equivalently, the resistance of $R_{V I}$ will be equal to $100 \mathrm{k} \Omega$. This will 
be also the impedance of the element at $100 \mathrm{~Hz}$. Therefore, fractional-order differentiators with unity-gain frequency $f_{0}=100 \mathrm{~Hz}$ and orders $\alpha=\{0.3,0.5,0.7\}$ will be realized.

In the case of 5th-order CFE approximation, the normalized transfer functions for orders $\alpha=\{0.3,0.5,0.7\}$ are the following:

$$
\begin{gathered}
H_{D, \mathrm{CFE}, 03}(s)=\frac{2.51 s^{5}+50.18 s^{4}+173.3 s^{3}+151.7 s^{2}+32.5 s+1}{s^{5}+32.5 s^{4}+151.7 s^{3}+173.3 s^{2}+50.18 s+2.51} . \\
H_{D, \mathrm{CFE}, 05}(s)=\frac{11 s^{5}+165 s^{4}+462 s^{3}+330 s^{2}+55 s+1}{s^{5}+55 s^{4}+330 s^{3}+462 s^{2}+165 s+11} . \\
H_{D, \mathrm{CFE}, 07}(s)=\frac{35.74 s^{5}+452.1 s^{4}+1105 s^{3}+686.9 s^{2}+95 s+1}{s^{5}+95 s^{4}+686.9 s^{3}+1105 s^{2}+452.1 s+35.74} .
\end{gathered}
$$

In the case of 5th-order Oustaloup's approximation, with $\left[\omega_{b}, \omega_{h}\right]=\left[10^{-2} \mathrm{rad} / \mathrm{s}\right.$, $10^{2} \mathrm{rad} / \mathrm{s}$ ], the corresponding normalized transfer functions of differentiator will be given by Eqs. (21)-(23), respectively.

$$
\begin{gathered}
H_{D, \text { OUST }, 03}(s)=\frac{3.98 s^{5}+142.9 s^{4}+700.9 s^{3}+531.7 s^{2}+62.36 s+1}{s^{5}+62.36 s^{4}+531.7 s^{3}+700.9 s^{2}+142.9 s+3.98} . \\
H_{D, \text { OUST }, 05}(s)=\frac{10 s^{5}+298.5 s^{4}+1218 s^{3}+768.5 s^{2}+74.97 s+1}{s^{5}+74.97 s^{4}+768.5 s^{3}+1218 s^{2}+298.5 s+10} . \\
H_{D, \text { OUST }, 07}(s)=\frac{25.12 s^{5}+623.6 s^{4}+2117 s^{3}+1111 s^{2}+90.14 s+1}{s^{5}+90.14 s^{4}+1111 s^{3}+2117 s^{2}+623.6 s+25.12} .
\end{gathered}
$$

Comparing the coefficients of Eqs. (18)-(23) with those of Eq. (13), and using Eqs. (14)-(15), the derived passive elements values (de-normalized at $100 \mathrm{~Hz}$ ) are summarized in Tables 5 and 6 , respectively.

Table 5. Values of passive elements for emulating fractional-order capacitors using CFE approximation.

\begin{tabular}{lccc}
\hline Passive element & F.O. capacitor $(\alpha=0.3)$ & F.O. capacitor $(\alpha=0.5)$ & F.O.capacitor $(\alpha=0.7)$ \\
\hline$C_{1}(\mathrm{nF})$ & 4.2 & 2.9 & 1.7 \\
$C_{2}(\mathrm{nF})$ & 31.5 & 26.5 & 22 \\
$C_{3}(\mathrm{nF})$ & 130 & 114 & 98.9 \\
$C_{4}(\mathrm{nF})$ & 512 & 446 & 389 \\
$C_{5}(\mu \mathrm{F})$ & 2.9 & 2.4 & 2 \\
$R(\mathrm{k} \Omega)$ & 10 & 10 & 10 \\
$R_{f}(\mathrm{k} \Omega)$ & 100 & 100 & 100 \\
$R_{V I}(\mathrm{k} \Omega)$ & 100 & 100 & 100 \\
$R_{0}(\mathrm{M} \Omega)$ & 0.4 & 1.1 & 3.6 \\
$R_{1}(\mathrm{k} \Omega)$ & 192 & 300 & 476 \\
$R_{2}(\mathrm{k} \Omega)$ & 122 & 140 & 166 \\
$R_{3}(\mathrm{k} \Omega)$ & 82 & 71 & 62 \\
$R_{4}(\mathrm{k} \Omega)$ & 52 & 33 & 21 \\
$R_{5}(\mathrm{k} \Omega)$ & 25 & 9 & 2.8 \\
\hline
\end{tabular}


Table 6. Values of passive elements for emulating fractional-order capacitors using the Oustaloup's approximation.

\begin{tabular}{lccc}
\hline Passive element & F.O. capacitor $(\alpha=0.3)$ & F.O. capacitor $(\alpha=0.5)$ & F.O. capacitor $(\alpha=0.7)$ \\
\hline$C_{1}(\mathrm{nF})$ & 2.5 & 2.1 & 1.8 \\
$C_{2}(\mathrm{nF})$ & 18.7 & 15.5 & 12.9 \\
$C_{3}(\mathrm{nF})$ & 121 & 100 & 83.5 \\
$C_{4}(\mathrm{nF})$ & 781 & 649 & 540 \\
$C_{5}(\mu \mathrm{F})$ & 5.71 & 4.75 & 3.95 \\
$R(\mathrm{k} \Omega)$ & 10 & 10 & 10 \\
$R_{f}(\mathrm{k} \Omega)$ & 100 & 100 & 100 \\
$R_{V I}(\mathrm{k} \Omega)$ & 100 & 100 & 100 \\
$R_{0}(\mathrm{M} \Omega)$ & 0.4 & 1 & 2.5 \\
$R_{1}(\mathrm{k} \Omega)$ & 229 & 398 & 692 \\
$R_{2}(\mathrm{k} \Omega)$ & 132 & 158 & 191 \\
$R_{3}(\mathrm{k} \Omega)$ & 63 & 52 \\
$R_{4}(\mathrm{k} \Omega)$ & 76 & 25 & 14 \\
$R_{5}(\mathrm{k} \Omega)$ & 44 & 10 & 4 \\
\hline
\end{tabular}

As a second design example, fractional-order inductors with inductance $L=159.15 \mathrm{H}$ at center frequency $f_{0}=100 \mathrm{~Hz}$ and orders $\beta=\{0.3,0.5,0.7\}$ will be emulated using the topology in Fig. 9. Using Eq. (4), the derived values of the pseudo-inductances are: $14.4 \mathrm{kH} / \mathrm{s}^{0.7}, 3.99 \mathrm{kH} / \mathrm{s}^{0.5}$, and $1.1 \mathrm{kH} / \mathrm{s}^{0.3}$, respectively. Owing to the fact that the impedance at unity-gain frequency will be equal to $100 \mathrm{k} \Omega$, then $g_{m, V I}=10 \mu \mathrm{S}$ and $R_{V I}=1 / g_{m, V I}=100 \mathrm{k} \Omega$. Fractional-order integrators with unity-gain frequency $f_{0}=100 \mathrm{~Hz}$ and orders $\beta=\{0.3,0.5,0.7\}$ will be employed for emulating the fractional-order inductors. Following a similar procedure as in the case of the fractional-order capacitor emulator, the derived values of the passive elements of the topology in Fig. 9 are provided in Tables 7 and 8, respectively.

Table 7. Values of passive elements for emulating fractional-order inductors using the CFE approximation.

\begin{tabular}{lccc}
\hline Passive element & F.O. inductor $(\beta=0.3)$ & F.O. inductor $(\beta=0.5)$ & F.O. inductor $(\beta=0.7)$ \\
\hline$C_{1}(\mathrm{nF})$ & 8.8 & 10.6 & 12.6 \\
$C_{2}(\mathrm{nF})$ & 49.5 & 56.8 & 65.1 \\
$C_{3}(\mathrm{nF})$ & 195 & 223 & 256 \\
$C_{4}(\mu \mathrm{F})$ & 0.82 & 0.95 & 1.1 \\
$C_{5}(\mu \mathrm{F})$ & 6 & 8.7 & 15.1 \\
$R(\mathrm{k} \Omega)$ & 10 & 10 & 10 \\
$R_{f}(\mathrm{k} \Omega)$ & 100 & 100 & 100 \\
$R_{V I}(\mathrm{k} \Omega)$ & 100 & 100 & 100 \\
$R_{0}(\mathrm{k} \Omega)$ & 25 & 9 & 2.8 \\
$R_{1}(\mathrm{k} \Omega)$ & 52 & 33 & 21 \\
$R_{2}(\mathrm{k} \Omega)$ & 82 & 71 & 62 \\
$R_{3}(\mathrm{k} \Omega)$ & 122 & 140 & 166 \\
$R_{4}(\mathrm{k} \Omega)$ & 192 & 300 & 476 \\
$R_{5}(\mathrm{M} \Omega)$ & 0.4 & 1.1 & 3.6 \\
\hline
\end{tabular}




\section{G. Tsirimokou et al.}

Table 8. Values of passive elements for emulating fractional-order inductors using the Oustaloup's approximation.

\begin{tabular}{lccc}
\hline Passive element & F.O. inductor $(\beta=0.3)$ & F.O. inductor $(\beta=0.5)$ & F.O. inductor $(\beta=0.7)$ \\
\hline$C_{1}(\mathrm{nF})$ & 4.4 & 5.3 & 6.4 \\
$C_{2}(\mathrm{nF})$ & 32.4 & 38.9 & 46.9 \\
$C_{3}(\mathrm{nF})$ & 210 & 252 & 303 \\
$C_{4}(\mu \mathrm{F})$ & 1.4 & 1.6 & 1.96 \\
$C_{5}(\mu \mathrm{F})$ & 9.9 & 11.9 & 14.3 \\
$R(\mathrm{k} \Omega)$ & 10 & 10 & 10 \\
$R_{f}(\mathrm{k} \Omega)$ & 100 & 100 & 100 \\
$R_{V I}(\mathrm{k} \Omega)$ & 100 & 100 & 100 \\
$R_{0}(\mathrm{k} \Omega)$ & 25 & 10 & 4 \\
$R_{1}(\mathrm{k} \Omega)$ & 44 & 25 & 14 \\
$R_{2}(\mathrm{k} \Omega)$ & 76 & 63 & 52 \\
$R_{3}(\mathrm{k} \Omega)$ & 132 & 158 & 191 \\
$R_{4}(\mathrm{k} \Omega)$ & 229 & 398 & 692 \\
$R_{5}(\mathrm{M} \Omega)$ & 0.4 & 1 & 2.5 \\
\hline
\end{tabular}

Using the AD $844^{33}$ discrete-component ICs as CFOAs and the OrCAD PSpice simulator, the obtained magnitude and phase responses in the cases of the emulation of fractional-order capacitors and inductors using the CFE approximation, along with the plots that correspond to the ideal (i.e. without approximation) cases, are given in Fig. 11. The corresponding plots, derived using the Oustaloup's approximation are provided in Fig. 12. The accuracy evaluation of the frequency responses from Figs. 11 and 12 is summarized in Tables 9 and 10, respectively, where it is

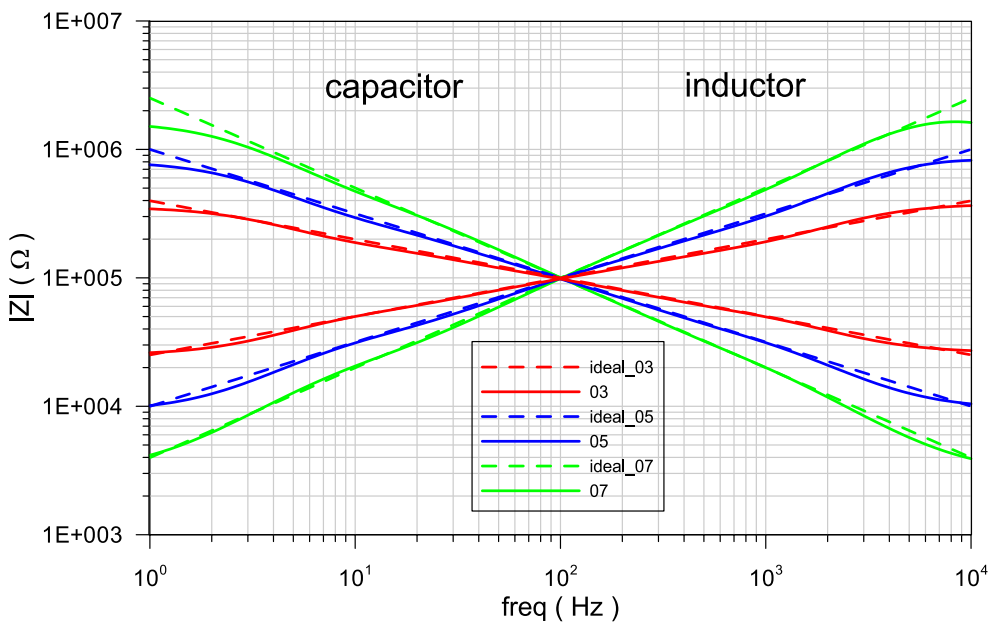

(a)

Fig. 11. Fractional-order capacitor and inductor impedance frequency responses, obtained from the circuit in Fig. 9 using the CFE approximation, (a) magnitude and (b) phase. 


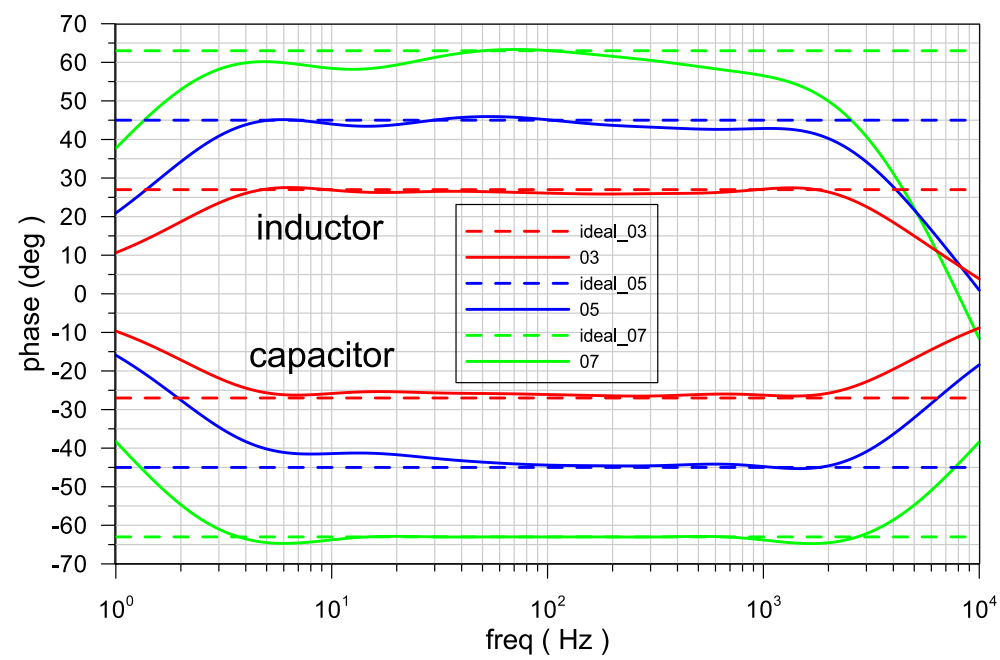

(b)

Fig. 11. (Continued)

verified the superiority of the CFE approximation in terms of phase accuracy and of the Oustaloup's method in terms of magnitude accuracy.

The time-domain behavior of the realized emulators has been evaluated through the stimulation of the circuit in Fig. 9, with a sinusoidal voltage with amplitude $100 \mathrm{mV}$ and frequency $100 \mathrm{~Hz}$. The derived current waveforms, obtained using the

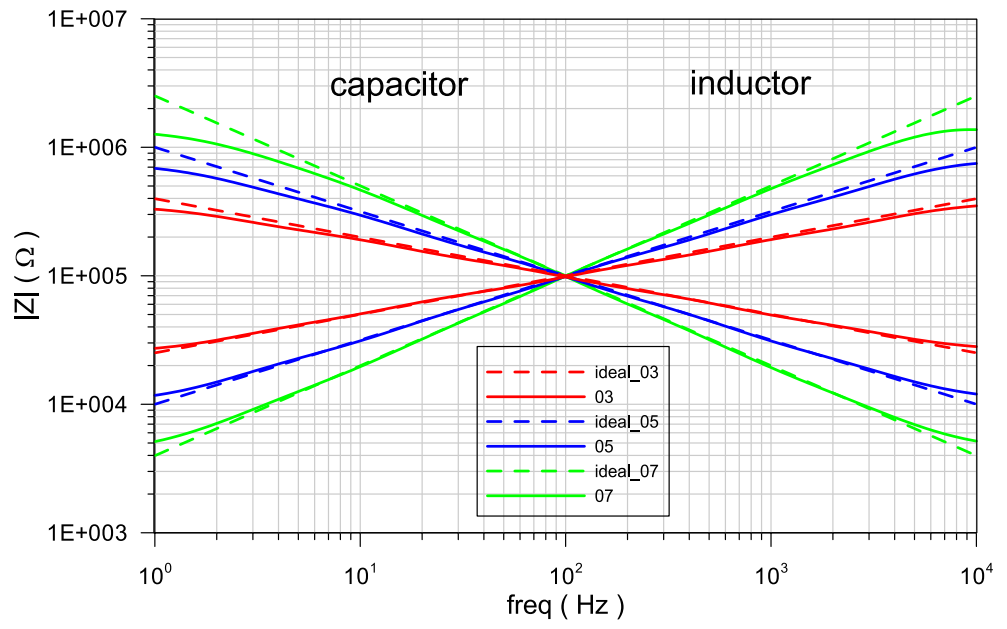

(a)

Fig. 12. Fractional-order capacitor and inductor impedance frequency responses, obtained from the circuit in Fig. 9 using the Oustaloup's approximation, (a) magnitude and (b) phase. 


\section{G. Tsirimokou et al.}

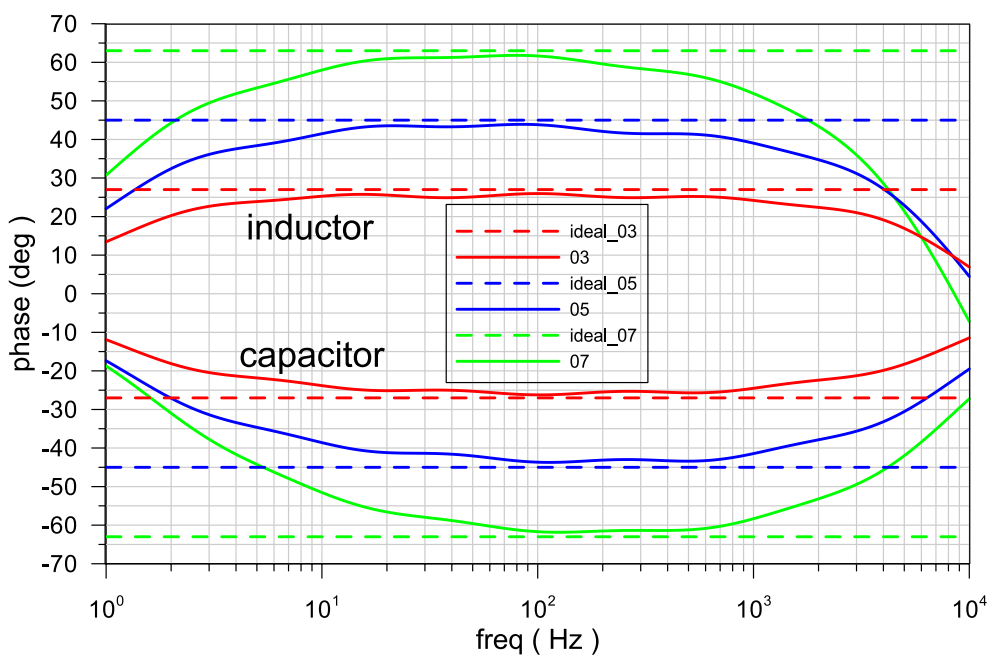

(b)

Fig. 12. (Continued)

Table 9. Accuracy performance of the CFE approximation for emulating fractional-order capacitors and inductors.

\begin{tabular}{lcc}
\hline Approximation & $\begin{array}{c}\text { Bandwidth for magnitude error }<5 \% \\
(\mathrm{kHz})\end{array}$ & $\begin{array}{c}\text { Bandwidth for phase error }<5 \% \\
(\mathrm{kHz})\end{array}$ \\
\hline $\mathrm{CFE}(\alpha=0.3)$ & {$[15 \mathrm{~Hz}, 2.4 \mathrm{kHz}]$} & {$[3 \mathrm{~Hz}, 2.1 \mathrm{kHz}]$} \\
$\mathrm{CFE}(\alpha=0.5)$ & {$[16 \mathrm{~Hz}, 1.8 \mathrm{kHz}]$} & {$[3 \mathrm{~Hz}, 2.6 \mathrm{kHz}]$} \\
$\mathrm{CFE}(\alpha=0.7)$ & {$[12 \mathrm{~Hz}, 2.2 \mathrm{kHz}]$} & {$[3 \mathrm{~Hz}, 3 \mathrm{kHz}]$} \\
$\mathrm{CFE}(\beta=0.3)$ & {$[15 \mathrm{~Hz}, 3 \mathrm{kHz}]$} & {$[4 \mathrm{~Hz}, 2.3 \mathrm{kHz}]$} \\
$\mathrm{CFE}(\beta=0.5)$ & {$[15 \mathrm{~Hz}, 3 \mathrm{kHz}]$} & {$[4 \mathrm{~Hz}, 1.5 \mathrm{kHz}]$} \\
$\mathrm{CFE}(\beta=0.7)$ & {$[11 \mathrm{~Hz}, 5 \mathrm{kHz}]$} & {$[2 \mathrm{~Hz}, 1 \mathrm{kHz}]$} \\
\hline
\end{tabular}

Table 10. Accuracy performance of the Oustaloup's approximation for emulating fractionalorder capacitors and inductors.

\begin{tabular}{lcc}
\hline Approximation & $\begin{array}{c}\text { Bandwidth for magnitude error }<5 \% \\
(\mathrm{kHz})\end{array}$ & $\begin{array}{c}\text { Bandwidth for phase error }<5 \% \\
(\mathrm{kHz})\end{array}$ \\
\hline OUST $(\alpha=0.3)$ & {$[8 \mathrm{~Hz}, 6.3 \mathrm{kHz}]$} & {$[50 \mathrm{~Hz}, 0.6 \mathrm{kHz}]$} \\
OUST $(\alpha=0.5)$ & {$[26 \mathrm{~Hz}, 4.5 \mathrm{kHz}]$} & {$[60 \mathrm{~Hz}, 0.7 \mathrm{kHz}]$} \\
OUST $(\alpha=0.7)$ & {$[15 \mathrm{~Hz}, 4.2 \mathrm{kHz}]$} & {$[50 \mathrm{~Hz}, 0.8 \mathrm{kHz}]$} \\
OUST $(\beta=0.3)$ & {$[2 \mathrm{~Hz}, 4.5 \mathrm{kHz}]$} & {$[70 \mathrm{~Hz}, 0.2 \mathrm{kHz}]$} \\
OUST $(\beta=0.5)$ & {$[2 \mathrm{~Hz}, 4.5 \mathrm{kHz}]$} & {$[13 \mathrm{~Hz}, 0.2 \mathrm{kHz}]$} \\
OUST $(\beta=0.7)$ & {$[4 \mathrm{~Hz}, 5 \mathrm{kHz}]$} & {$[14 \mathrm{~Hz}, 0.2 \mathrm{kHz}]$} \\
\hline
\end{tabular}




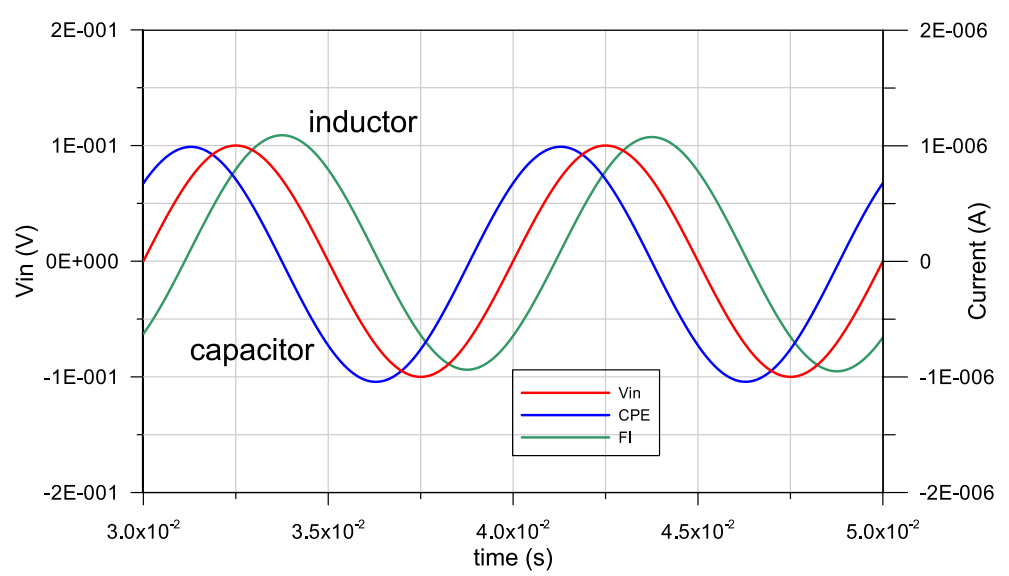

Fig. 13. Input-output waveforms of the FBD in Fig. 1 in the case of fractional-order capacitor $(\alpha=0.5)$ and fractional-order inductor $(\beta=0.5)$.

CFE approximation for $\alpha=\beta=0.5$, are demonstrated in Fig. 13 and confirm the correct operation of the circuit.

The sensitivity performance of the implemented emulators has been evaluated through the utilization of the Monte-Carlo method offered by the Advanced Analysis Tool of the PSpice and assuming 5\% random variations of the passive elements. The

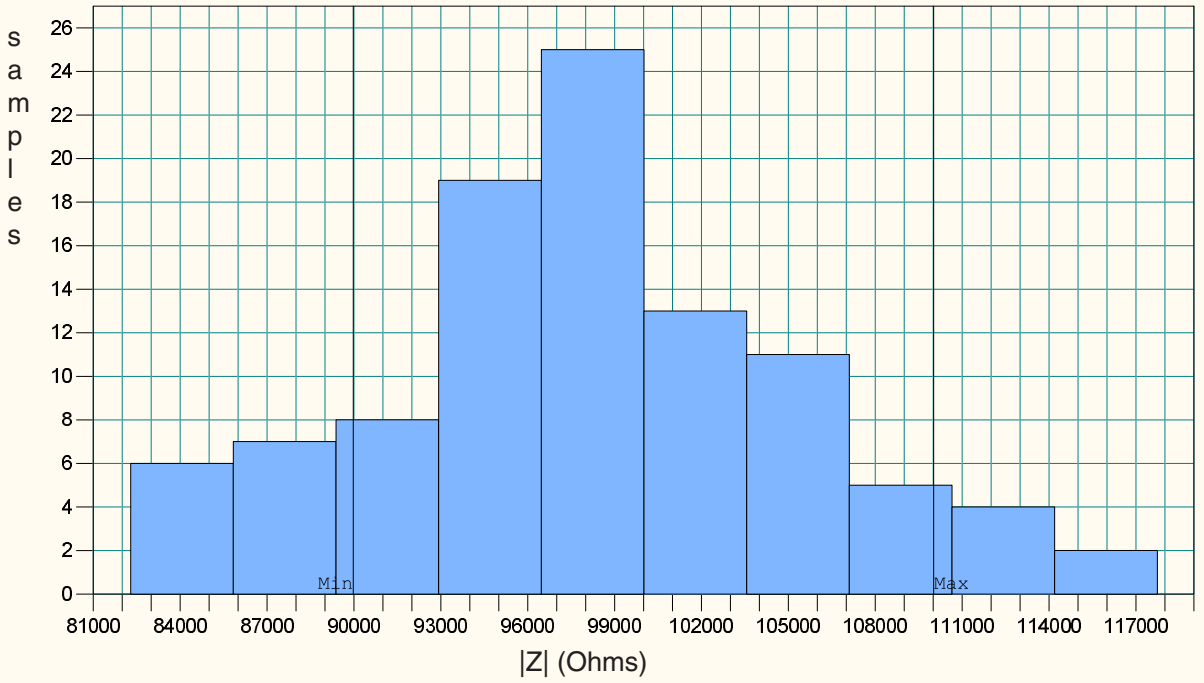

(a)

Fig. 14. Monte-Carlo histograms of the impedance response of the fractional-order capacitor at $100 \mathrm{~Hz}$, (a) magnitude and (b) phase. 


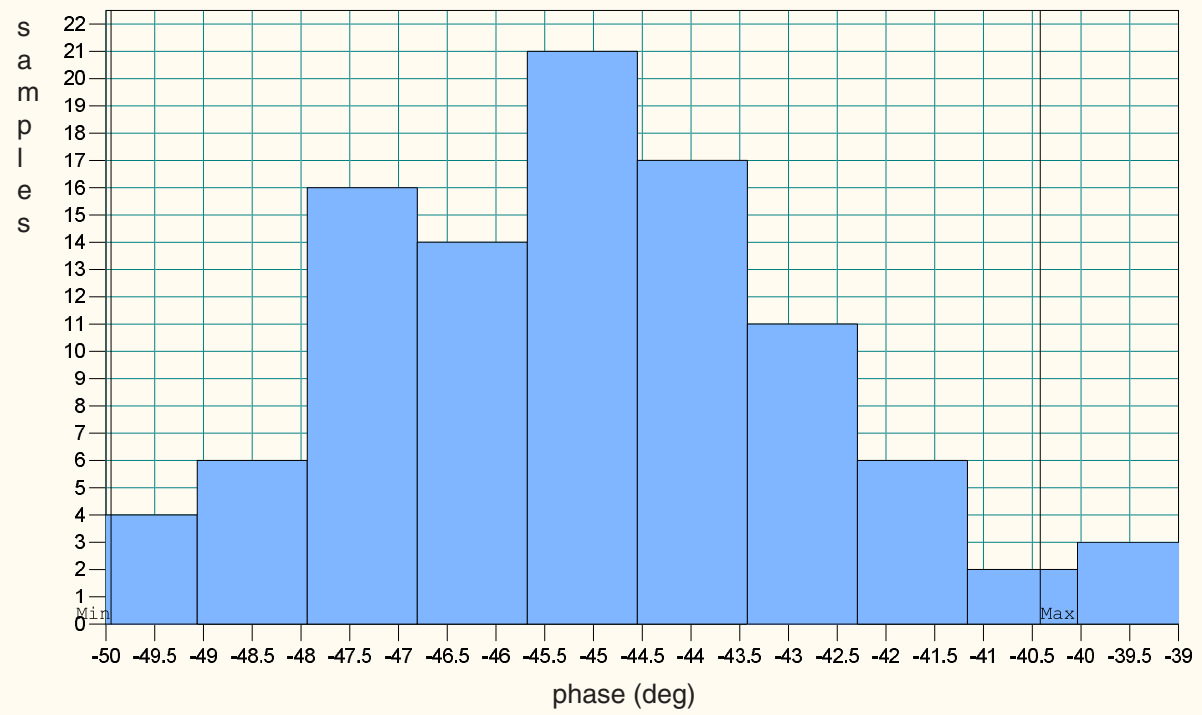

(b)

Fig. 14. (Continued)

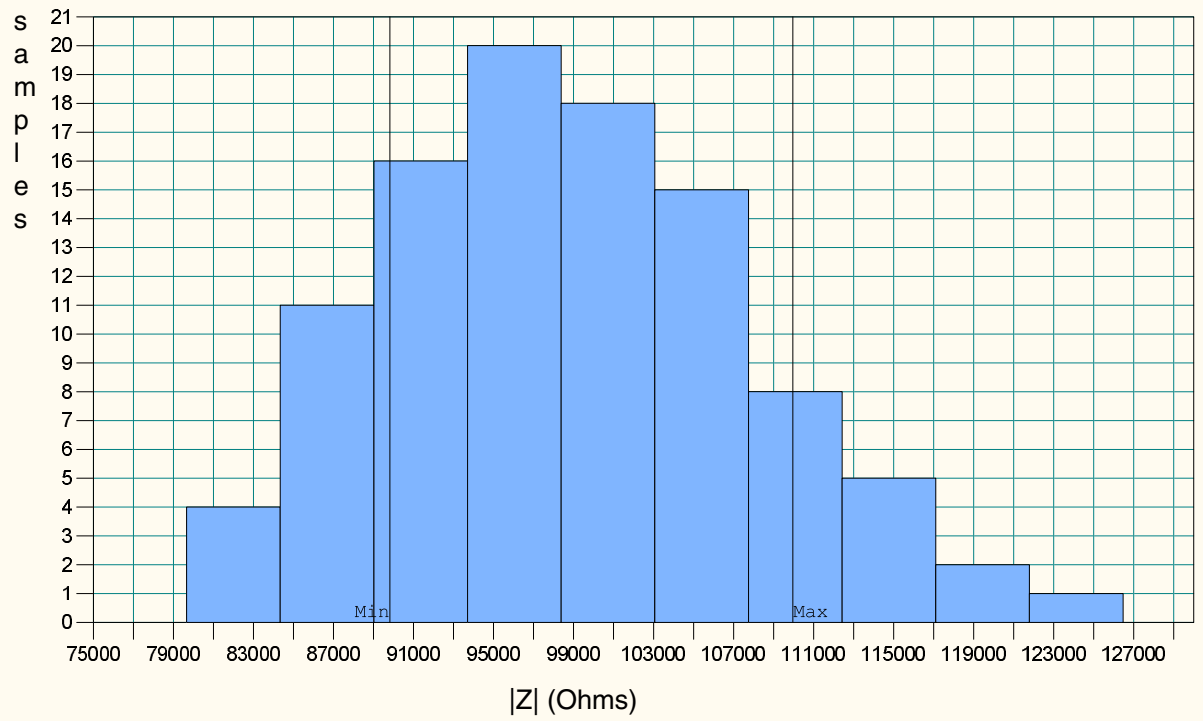

(a)

Fig. 15. Monte-Carlo histograms of the impedance response of the fractional-order inductor at $100 \mathrm{~Hz}$, (a) magnitude and (b) phase. 


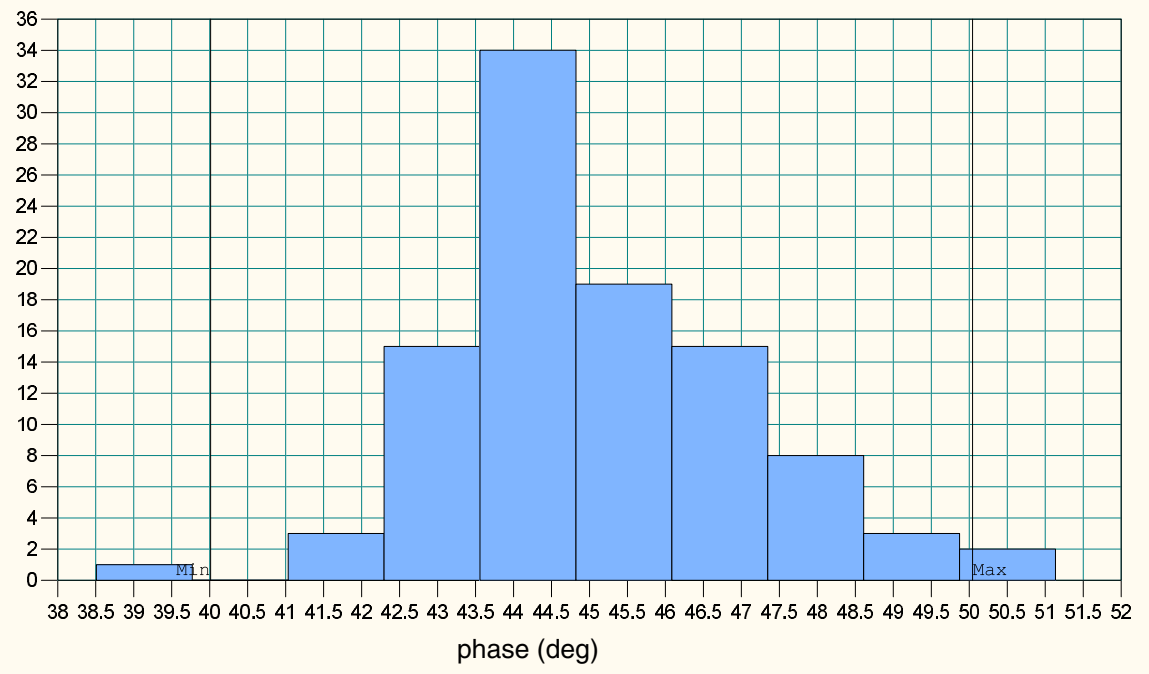

(b)

Fig. 15. (Continued)

obtained histograms, for $N=50$ runs, using the CFE approximation for $\alpha=\beta=0.5$, are demonstrated in Figs. 14 and 15. The mean and the standard deviation values of the magnitude of the impedance at $100 \mathrm{~Hz}$, denoted as $E\left(\operatorname{mag}\left(Z_{I N}\right) @ 100 \mathrm{~Hz}\right)$ and $\sigma\left(\operatorname{mag}\left(Z_{I N}\right) @ 100 \mathrm{~Hz}\right)$, were $\{97.8 \mathrm{k} \Omega, 7.3 \mathrm{k} \Omega\}$, while the mean and the standard deviation values of the phase of the impedance at $100 \mathrm{~Hz}$, denoted as $E\left(\operatorname{phase}\left(Z_{I N}\right) @ 100 \mathrm{~Hz}\right)$ and $\sigma\left(\operatorname{phase}\left(Z_{I N}\right) @ 100 \mathrm{~Hz}\right)$, were $\{-44.3 \mathrm{deg}, 2.3$ $\operatorname{deg}\}$ in the case of the fractional-order capacitor. In the the case of the fractional-order inductor, the corresponding values were $\{98.5 \mathrm{k} \Omega, 8.8 \mathrm{k} \Omega\}$ and $\{43.9 \mathrm{deg}, 2 \mathrm{deg}\}$,

Table 11. Sensitivity performance of fractional-order capacitor $(\alpha=0.5)$ and inductor $(\beta=0.5)$ using different circuit topology implementations from Figs. $7-10$.

\begin{tabular}{lcccc}
\hline & \multicolumn{3}{c}{ Circuit topology using } \\
\cline { 2 - 5 } Performance factor & op-amps & CCIIs & CFOAs & OTAs \\
\hline$E\left(\operatorname{mag}\left(Z_{\mathrm{IN}}\right) @ 100 \mathrm{~Hz}\right)(\alpha=0.5)$ & $98.8 \mathrm{k} \Omega$ & $108.6 \mathrm{k} \Omega$ & $97.8 \mathrm{k} \Omega$ & $99.1 \mathrm{k} \Omega$ \\
$\sigma\left(\operatorname{mag}\left(Z_{\mathrm{IN}}\right) @ 100 \mathrm{~Hz}\right)(\alpha=0.5)$ & $5.3 \mathrm{k} \Omega$ & $5.5 \mathrm{k} \Omega$ & $7.3 \mathrm{k} \Omega$ & $3.7 \mathrm{k} \Omega$ \\
$E\left(\operatorname{phase}\left(Z_{\mathrm{IN}}\right) @ 100 \mathrm{~Hz}\right)(\alpha=0.5)$ & $-43.3 \mathrm{deg}$ & $-43.9 \mathrm{deg}$ & $-44.3 \mathrm{deg}$ & $-44.7 \mathrm{deg}$ \\
$\sigma\left(\operatorname{phase}\left(Z_{\mathrm{IN}}\right) @ 100 \mathrm{~Hz}\right)(\alpha=0.5)$ & $3.6 \mathrm{deg}$ & $2.5 \mathrm{deg}$ & $2.3 \mathrm{deg}$ & $3 \mathrm{deg}$ \\
$E\left(\operatorname{mag}\left(Z_{\mathrm{IN}}\right) @ 100 \mathrm{~Hz}\right)(\beta=0.5)$ & $99.5 \mathrm{k} \Omega$ & $109.7 \mathrm{k} \Omega$ & $98.5 \mathrm{k} \Omega$ & $100.1 \mathrm{k} \Omega$ \\
$\sigma\left(\operatorname{mag}\left(Z_{\mathrm{IN}}\right) @ 100 \mathrm{~Hz}\right)(\beta=0.5)$ & $7.6 \mathrm{k} \Omega$ & $7.7 \mathrm{k} \Omega$ & $8.8 \mathrm{k} \Omega$ & $5.6 \mathrm{k} \Omega$ \\
$E\left(\operatorname{phase}\left(Z_{\mathrm{IN}}\right) @ 100 \mathrm{~Hz}\right)(\beta=0.5)$ & $46.2 \mathrm{deg}$ & $44.4 \mathrm{deg}$ & $43.9 \mathrm{deg}$ & $46 \mathrm{deg}$ \\
$\sigma\left(\operatorname{phase}\left(Z_{\mathrm{IN}}\right) @ 100 \mathrm{~Hz}\right)(\beta=0.5)$ & $2.5 \mathrm{deg}$ & $2.1 \mathrm{deg}$ & $2 \mathrm{deg}$ & $2 \mathrm{deg}$ \\
\hline
\end{tabular}




\section{G. Tsirimokou et al.}

respectively. In addition, the sensitivity performance characteristics of the corresponding implementations performed using op-amps (Fig. 7), CCIIs (Fig. 8), and OTAs (Fig. 10) as active elements are summarized in Table 11. According to the provided results, it is derived that the implementation with CFOAs has increased sensitivity to the components values variations and this is the price paid for the achieved reduction of the active component count.

\section{Conclusions}

The performance of typical approximations for implementing fractional-order differentiators and integrators has been evaluated in this paper. Thus, the important conclusion is that the CFE approximation is more efficient in terms of phase accuracy, while the Oustaloup's approximation offers superiority in the magnitude approximation. With respect to the discrete-component implementation using commercially available active elements, the employment of CFOAs as active elements offers the benefits of reduced active component count. The verification of these derivations has been performed through simulation results.

\section{Acknowledgments}

This paper is based upon work from COST Action CA15225, a network supported by COST (European Cooperation in Science and Technology).

Research described in this paper was financed by the National Sustainability Program under grant LO1401 and by the Czech Science Foundation under grant no. 16-06175S. For the research, infrastructure of the SIX Center was used.

A preliminary version of this paper has been presented at the 2017 40th International Conference on Telecommunications and Signal Processing (TSP). ${ }^{34}$

\section{References}

1. A. S. Elwakil, Fractional-order circuits and systems: An emerging interdisciplinary research area, IEEE Circuits Syst. Mag. 10(4) (2010) 40-50.

2. A. G. Radwan, A. M. Soliman and A. S. Elwakil, First-order filters generalized to the fractional domain, J. Circuits, Syst. Comput. 17(1) (2008) 55-66.

3. T. J. Freeborn, B. Maundy and A. S. Elwakil, Field programmable analogue array implementation of fractional step filters, IET Circuits, Dev. Syst. 4(6) (2010) 514-524.

4. A. G. Radwan and K. N. Salama, Passive and active elements using fractional $L_{\beta} C_{\alpha}$ circuit, IEEE Trans. Circuits Syst. I, Regul. Pap. 58(10) (2011) 2388-2397.

5. A. G. Radwan and M. E. Fouda, Optimization of fractional-order RLC filters, Circuits, Syst. Signal Process. 32(5) (2013) 2097-2118.

6. M. C. Tripathy, D. Mondal, K. Biswas and S. Sen, Experimental studies on realization of fractional inductors and fractional-order bandpass filters, Int. J. Circuit Theory Appl. 43(9) (2015) 1183-1196. 
7. R. Sotner, J. Jerabek, N. Herencsar, J. Petrzela, T. Dostal and K. Vrba, First-order adjustable transfer sections for synthesis suitable for special purposes in constant phase block approximation, AEU-Int. J. Electron. Commun. 69(9) (2015) 1334-1345.

8. I. Dimeas, G. Tsirimokou, C. Psychalinos and A. S. Elwakil, Experimental verification of fractional-order filters using a reconfigurable fractional-order impedance emulator, $J$. Circuits, Syst. Comput. 26(9) (2017) 1750142.

9. J. Jerabek, R. Sotner, J. Dvorak, J. Polak, D. Kubanek, N. Herencsar and J. Koton, Reconfigurable fractional-order filter with electronically controllable slope of attenuation, pole frequency and type of approximation, J. Circuits, Syst. Comput. 26(10) (2017) 1750157.

10. L. A. Said, A. G. Radwan, A. H. Madian and A. M. Soliman, Fractional order oscillators based on operational transresistance amplifiers, AEU-Int. J. Electron. Commun. 69(7) (2015) 988-1003.

11. A. G. Radwan, B. J. Maundy and A. S. Elwakil, Fractional-order oscillators, Oscillator Circuits: Frontiers in Design, Analysis and Applications, ed. Y. Nishio (The Institution of Engineering and Technology, UK, 2016), pp. 25-49.

12. D. Kubánek, F. Khateb, G. Tsirimokou and C. Psychalinos, Practical design and evaluation of fractional-order oscillator using differential voltage current conveyors, Circuits, Syst. Signal Process. 35(6) (2016) 2003-2016.

13. A. Kartci, N. Herencsar, J. Koton, L. Brancik, K. Vrba, G. Tsirimokou and C. Psychalinos, Fractional-order oscillator design using unity-gain voltage buffers and OTAs, in IEEE 60th Int. Midwest Sympo. Circuits and Systems (MWSCAS), (IEEE, 2017), pp. $555-558$.

14. C. Vastarouchas, G. Tsirimokou, T. J. Freeborn and C. Psychalinos, Emulation of an electrical-analogue of a fractional-order human respiratory mechanical impedance model using OTA topologies, AEU-Int. J. Electron. Commun. 78 (2017) 201-208.

15. A. M. AbdelAty, A. Radwan, A. Elwakil and C. Psychalinos, Transient and steady-state response of a fractional-order dynamic PV model under different loads, J. Circuits, Syst. Comput. 27(02) (2018) 1850023.

16. S. Westerlund and L. Ekstam, Capacitor theory, IEEE Trans. Dielect. Electr. Insul. 1(5) (1994) 826-839.

17. R. Caponetto, S. Graziani, F. L. Pappalardo and F. Sapuppo, Experimental characterization of ionic polymer metal composite as a novel fractional order element, Adv. Math. Phys. 2013 (2013) 1-10.

18. A. Agambayev, S. Patole, M. Farhat, A. Elwakil, H. Bagci and K. N. Salama, Ferroelectric fractional-order capacitors, ChemElectroChem 4(11) (2017) 2807-2813.

19. D. A. John, S. Banerjee, G. W. Bohannan and K. Biswas, Solid-state fractional capacitor using MWCNT-epoxy nanocomposite, Appl. Phys. Lett. 110(16) (2017) 163504.

20. C. Halijak, An RC impedance approximant to $(1 / s)^{1 / 2}$, IEEE Trans. Circuit Theory 11(4) (1964) 494-495.

21. G. Carlson and C. Halijak, Approximation of fractional capacitors $(1 / s)^{1 / n}$ by a regular Newton process, IEEE Trans. Circuit Theory 11(2) (1964) 210-213.

22. J. Valsa and J. Vlach, RC models of a constant phase element, Int. J. Circuit Theory Appl. 41(1) (2013) 59-67.

23. A. S. Ali, A. G. Radwan and A. M. Soliman, Fractional order Butterworth filter: Active and passive realizations, IEEE J. Emerg. Sel. Top. Circuits Syst. 3(3) (2013) 346-354.

24. G. Tsirimokou, C. Psychalinos and A. S. Elwakil, Emulation of a constant phase element using operational transconductance amplifiers, Analog Integr. Circuits Signal Process. 85(3) (2015) 413-423. 


\section{G. Tsirimokou et al.}

25. G. Tsirimokou, C. Psychalinos, A. S. Elwakil and K. N. Salama, Electronically tunable fully integrated fractional-order resonator, IEEE Trans. Circuits Syst, II, Express Briefs in print (2017). DOI: 10.1109/TCSII.2017.2684710.

26. B. Krishna, Studies on fractional order differentiators and integrators: A survey, Signal Process. 91(3) (2011) 386-426.

27. A. Oustaloup, F. Levron, B. Mathieu and F. M. Nanot, Frequency-band complex noninteger differentiator: Characterization and synthesis, IEEE Trans. Circuits Syst. I, Fundam. Theory Appl. 47(1) (2000) 25-39.

28. A. Tepljakov, E. Petlenkov and J. Belikov, FOMCON: A MATLAB toolbox for fractional-order system identification and control, Int. J. Microelectron. Comput. Sci. 2(2) (2011) 51-62.

29. T. Deliyannis, Y. Sun and J. K. Fidler, Continuous-Time Active Filter Design (CRC Press, US, 1998).

30. P. A. Mohan, Current-Mode VLSI Analog Filters: Design and Applications (Springer Science \& Business Media, US, 2012).

31. R. Senani, D. Bhaskar, A. Singh and V. Singh, Current Feedback Operational Amplifiers and Their Applications (Springer Science \& Business Media, US, 2013).

32. Y. Sun, Design of High Frequency Integrated Analogue Filters, No. 14 (Institution of Electrical Engineers (IEE), UK, 2002).

33. AD844, 60MHz 2000V/ $\mu$ s monolithic op-amp, Analog Devices, rev (2009).

34. G. Tsirimokou, A. Kartci, J. Koton, N. Herencsar and C. Psychalinos, Experimental verification of filters using fractional-order capacitor and inductor emulators, 40th Int. Conf. Telecommunications and Signal Processing (TSP) (IEEE, 2017), pp. 706-709. 